and morphologic view of the lesion. ${ }^{3}$ The angiocardiogram is not as important as the echocardiogram in delineating the aneurysm. ${ }^{2}$ In the present case, the left ventriculogram in the right anterior oblique and 4-chamber view delineated the mitral regurgitation and the aneurysm of the anterior leaflet. Intraoperatively, it is important to determine the precise pathologic anatomy. Depending on the nature and site of the mitral lesion, conservation of the mitral valve could be possible, especially if the aneurysm is small or located on the posterior mitral leaflet. ${ }^{3}$ However, with large aneurysm such as in the present case with nearly $50 \%$ leaflet involvement and involvement of the subvalvar apparatus, replacement of the valve is the only choice.

\section{CONCLUSIONS}

True aneurysm of the mitral valve is rare entity. Transesophageal echocardiography is an important noninvasive diagnostic modality. The decision to repair or replace the valve is mainly dependent on the size, the site of the aneurysm, the condition of the surrounding tissue, and subvalvar involvement.

\section{References}

1. Saphir O, Leroy EP. True aneurysms of the mitral valve in subacute bacterial endocarditis. Am J Pathol. 1948;24:83-95.

2. Enia F, Celona G, Filippone V. Echocardiographic detection of mitral valve aneurysm in patient with infective endocarditis. Br Heart J. 1983;49:98-100.

3. Northridge DB, Gnanapragasam JP, Houston AB. Diagnosis of mitral valve aneurysm by transoesophageal echocardiography. Br Heart J. 1991;65:227-8.

\title{
Nonintubated thoracoscopic surgery for pulmonary lesions in both lungs
}

\author{
Tung-Ming Tsai, MD, and Jin-Shing Chen, MD, PhD, Taipei, Taiwan
}

Thoracoscopic resections for pulmonary lesions in both lungs are usually performed under conditions of general anesthesia with double-lumen endotracheal intubation and sequential single-lung ventilation. ${ }^{1}$ A newly developed nonintubated technique that uses thoracic epidural anesthesia and sedation has been introduced for thoracoscopic resection of unilateral pulmonary lesions, with satisfactory results. ${ }^{2-5}$ Nonintubated thoracoscopic surgery for lesions in both lungs, however, has not previously been reported. Here we report a case of successful resection with a nonintubated thoracoscopic technique for bilateral pulmonary lesions. Our results indicate that nonintubated thoracoscopic surgery can be used in a specific group of patients.

\section{CLINICAL SUMMARY}

A 57-year-old nonsmoking woman was referred to our hospital for undetermined bilateral pulmonary lesions. She had a medical history of Sjögren syndrome complicated

\footnotetext{
From the Divisions of Experimental Surgery, and Thoracic Surgery, Department of Surgery, National Taiwan University Hospital and National Taiwan University College of Medicine, Taipei, Taiwan.

Disclosures: Authors have nothing to disclose with regard to commercial support.

Received for publication March 13, 2012; revisions received May 21, 2012; accepted for publication June 12, 2012; available ahead of print July 12, 2012.

Address for reprints: Jin-Shing Chen, MD, PhD, Division of Thoracic Surgery, Department of Surgery, National Taiwan University Hospital, No. 7, Chung Shan S Rd, Taipei, Taiwan (E-mail: chenjs@ntu.edu.tw).

J Thorac Cardiovasc Surg 2012;144:e95-7

0022-5223/\$36.00

Copyright (C) 2012 by The American Association for Thoracic Surgery

http://dx.doi.org/10.1016/j.jtcvs.2012.06.025
}

with xerostomia for more than 10 years. Serial thoracic computed tomographic scans showed 2 ground-glass opacities: 1 corresponded to a $0.5-\mathrm{cm}$ previously undetected lesion in the right lower lobe, and the other corresponded to a $0.7-\mathrm{cm}$ stationary lesion in the left lower lobe (Figure 1). The patient had a family history of lung cancer, and computed tomographic findings suggested the presence of multiple early lung cancers. The preoperative forced expiratory volume in 1 second was $122 \%$ of the prediction value. After discussion with our surgical team, the patient opted for nonintubated anesthesia during thoracoscopic resection to avoid the airway mucosal injury caused by severe xerostomia after endotracheal intubation.

In the operating room, the patient was medicated before surgery with an intravenous infusion of $50 \mu \mathrm{g}$ fentanyl. Thoracic epidural anesthesia was administered in the T5-6 thoracic interspace by continuous infusion of $2 \%$ lidocaine. The patient was then sedated with an intravenous infusion of propofol $(10 \mathrm{mg} / \mathrm{mL})$, with a target-controlled infusion method used to maintain her in a mildly sedated, but communicative and cooperative, state (Ramsay sedation score III). During the procedure, the patient breathed oxygen through a ventilation mask.

Subsequently, bilateral sequential thoracoscopic surgery was performed with the patient in the left decubitus position. The right pulmonary lesion was identified by preoperative computed tomographically guided hookwire localization. During right thoracoscopy, the right lung collapsed gradually under spontaneous breathing. To inhibit coughing during thoracoscopic manipulation, a vagal block 

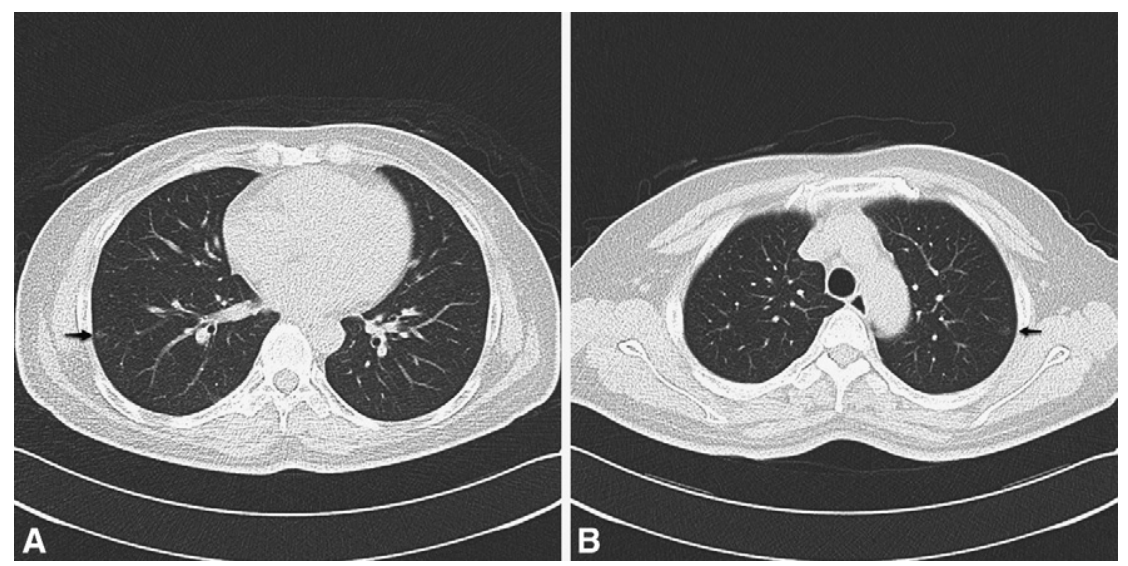

FIGURE 1. Thoracic computed tomographic scans showing 2 ground-glass opacities. A, A 0.5 -cm lesion in the right lower lobe (arrow). B, A 0.7 -cm lesion in the left lower lobe (arrow).

was produced by infiltrating $2 \mathrm{~mL}$ of $2 \%$ lidocaine adjacent to the vagus nerve. ${ }^{4}$ Stapled-wedge resection was performed with the 3-port procedure. After the operation, a $28 \mathrm{~F}$ chest tube was inserted, and the incisions were closed. The collapsed right lung was reexpanded with positivepressure mask ventilation and negative-pressure suction through the chest tube. The patient was then turned to the right decubitus position, and the resection procedure was repeated for the left pulmonary lesion. The total operation duration was 185 minutes. Postoperatively, immediate arterial blood gas analysis showed normocapnia, and chest radiographic scan showed complete expansion of both lung fields. The pathologic report showed bronchioloalveolar carcinoma in the left lung and a pulmonary meningotheliallike tumor in the right lung (Figure 2). The patient was discharged uneventfully on the 5th postoperative day.

\section{DISCUSSION}

The use of double-lumen endotracheal intubation with single-lung ventilation has been considered mandatory for thoracoscopic surgery. Many East Asian patients, however, especially women, have small bodies with a small tracheal caliber, and are susceptible to complications related to double-lumen endotracheal intubation or mechanical ventilation, such as hoarseness, subglottic stenosis, and pneumonia. With the combination of thoracic epidural anesthesia, sedation, and vagal blockade, we previously demonstrated that lobectomy and wedge resection can be performed without endotracheal intubation. ${ }^{4,5}$ In this report, we have extended the application of nonintubated thoracoscopic surgery to a patient with bilateral pulmonary lesions.

Some concerns might arise with the use of nonintubated anesthesia for bilateral pulmonary resections. First, manipulation and resection of the lung can induce a cough reflex. Second, prolonged sequential single-lung breathing can lead to hypoxia and hypercapnia, which may require conversion to general anesthesia with intubation. In this patient, we used lidocaine for intrathoracic vagal blockade, which effectively abolished the cough reflex during the operation. ${ }^{4}$ In addition, small stapled lung wedge resections in patients with good pulmonary function are simple and safe. They should not cause respiratory failure necessitating emergency intubation.
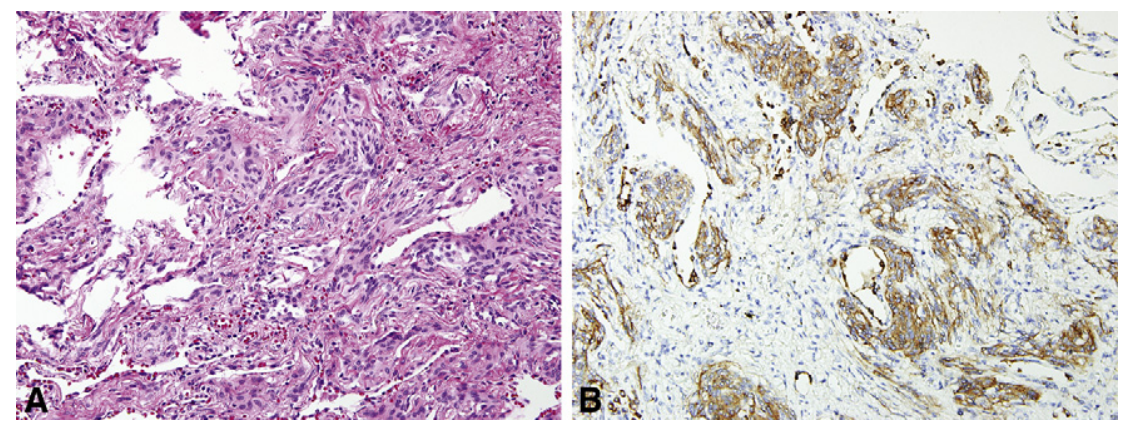

FIGURE 2. A, Microscopic examination of the right lung nodule showing clusters of epithelioid cells with bland-looking nuclei and indistinct cell borders (original magnification $\times 66$ ). B, Immunohistochemically, the epithelioid cells were immunoreactive for epithelial membrane antigen (original magnification $\times 66$ ) and negative for cytokeratin (data not shown). 
The final pathologic description of the right lung nodule was pulmonary meningotheliallike tumor. The clinicopathologic characteristic of this benign tumor remain unclear, but it is usually very tiny $(1-3 \mathrm{~mm})$ and discovered incidentally after lung resection for other lesions. Presentation as a solitary nodule $5 \mathrm{~mm}$ in size, as in our patient, is not common.

In conclusion, the successful treatment in this patient suggests that nonintubated thoracoscopic operation may be feasible and safe in the treatment of selected patients with bilateral small peripheral pulmonary lesions and good preoperative cardiopulmonary function.

\section{References}

1. Chou SH, Li HP, Lee JY, Chang SJ, Lee YL, Chang YT, et al. Is prophylactic treatment of contralateral blebs in patients with primary spontaneous pneumothorax indicated? J Thorac Cardiovasc Surg. 2010;139:1241-5.

2. Pompeo E, Tacconi F, Mineo D, Mineo TC. The role of awake video-assisted thoracoscopic surgery in spontaneous pneumothorax. J Thorac Cardiovasc Surg. 2007; 133:786-90

3. Pompeo E, Mineo TC. Awake pulmonary metastasectomy. J Thorac Cardiovasc Surg. 2007;133:960-6.

4. Chen JS, Cheng YJ, Hung MH, Tseng YD, Chen KC, Lee YC. Nonintubated thoracoscopic lobectomy for lung cancer. Ann Surg. 2011;254:1038-43.

5. Tseng YD, Cheng YJ, Hung MH, Chen KC, Chen JS. Nonintubated needlescopic video-assisted thoracic surgery for management of peripheral lung nodules. Ann Thorac Surg. 2012;93:1049-54.

\title{
Acute ascending aortic dissection during transaortic balloon- expandable aortic valve implantation
}

\author{
Augusto D'Onofrio, MD, ${ }^{\mathrm{a}}$ Chiara Tessari, MD, ${ }^{\mathrm{a}}$ Roberto Bianco, $\mathrm{MD},{ }^{\mathrm{a}}$ Giambattista Isabella, MD, \\ Guido Di Gregorio, $\mathrm{MD},{ }^{\mathrm{c}}$ and Gino Gerosa, $\mathrm{MD},{ }^{\mathrm{a}}$ Padova, Italy
}

Transcatheter aortic valve replacement (TAVR) has shown good early and midterm results in high-risk or inoperable patients with severe symptomatic aortic valve stenosis. ${ }^{1}$ TAVR is generally accomplished with either antegrade transapical or retrograde transfemoral access. If these approaches are not technically possible, transaortic TAVR (Tao-TAVR) is feasible and effective. Tao-TAVR can be performed through either a ministernotomy or a minithoracotomy. ${ }^{2,3}$ The advantages of Tao-TAVR are mainly related to (1) the short distance between the delivery system and the aortic annulus that enables a precise valve deployment and (2) the possibility to schedule for TAVR patients who have contraindications for the transapical and/or transfemoral approach. Nowadays there is a wide experience with both transapical and transfemoral TAVR, and consequently their related complications are known, predictable, and manageable. ${ }^{4}$ On the other hand, Tao-TAVR is a relatively new technique that is performed without specifically designed devices, and its possible complications are still not widely known and described. We describe a case of acute ascending aortic dissection during Tao-TAVR that required emergency conversion to open surgery.

\footnotetext{
From the Divisions of Cardiac Surgery, ${ }^{\mathrm{a}}$ Cardiology, ${ }^{\mathrm{b}}$ and Anesthesiology, ${ }^{\mathrm{c}}$ University of Padova, Padova, Italy.

Disclosures: Authors have nothing to disclose with regard to commercial support.

Received for publication Jan 20, 2012; revisions received April 3, 2012; accepted for publication June 12, 2012; available ahead of print July 16, 2012.

Address for reprints: Augusto D'Onofrio, MD, Division of Cardiac Surgery, University of Padova, via Giustiniani 2, CAP 35128, Padova, Italy (E-mail: adonofrio@ hotmail.it).

J Thorac Cardiovasc Surg 2012;144:e97-9

$0022-5223 / \$ 36.00$

Copyright (c) 2012 by The American Association for Thoracic Surgery

http://dx.doi.org/10.1016/j.jtcvs.2012.06.032
}

\section{CLINICAL SUMMARY}

A 79-year-old woman with severe symptomatic aortic valve stenosis was admitted to our department for surgical treatment. She had a history of pulmonary edema and was in New York Heart Association functional class III. Associated comorbidities were rheumatoid arthritis, osteoporosis, and a history of spontaneous cerebral hemorrhage. The aortic valve area was $0.4 \mathrm{~cm}^{2} / \mathrm{m}^{2}$, and the mean and peak transaortic gradients were $23 \mathrm{~mm} \mathrm{Hg}$ and $38 \mathrm{~mm} \mathrm{Hg}$, respectively. Preoperative echocardiography showed a severe diffuse left ventricular hypokinesia. The left ventricular ejection fraction was $26 \%$ and the end-diastolic volume index was $165 \mathrm{~mL} / \mathrm{m}^{2}$. Dobutamine stress echocardiography showed an improvement in left ventricular ejection fraction that reached $35 \%$ as well as an increase of peak gradient that reached $65 \mathrm{~mm} \mathrm{Hg}$. Coronary artery angiography showed diffuse coronary artery disease with a $60 \%$ stenosis of the circumflex coronary artery and an $85 \%$ stenosis of a small posterolateral branch of the right coronary artery. Both vessels were judged as not amenable for either surgical or percutaneous revascularization. The nature of left ventricular dysfunction was related to the diffuse coronary artery disease and to the longstanding aortic valve disease. Logistic EuroSCOREs I and II were 20\% and 12\%, respectively. The Society of Thoracic Surgeons risk of mortality was $18 \%$.

Owing to the high surgical risk, the patient was scheduled for TAVR with the Sapien XT bioprosthesis (Edwards Lifesciences, Irvine, Calif). The aortic valve annulus, measured with transesophageal echocardiography and with cardiac computed tomographic scan, was $24 \mathrm{~mm}$ and consequently a $26-\mathrm{mm}$ prosthesis was chosen. The diameter of the 